\title{
A avaliatividade na socioconstrução do self: uma análise da autoconstrução reflexiva da identidade hegemônica patriarcal
}

\author{
Thais Regina Santos Borges \\ Pontifícia Universidade Católica do Rio de Janeiro - PUC-Rio / CAPES
}

\begin{abstract}
Resumo
Este estudo investiga como a identidade masculina hegemônica (re)produzida por um humorista brasileiro em um evento discursivo na mídia tradicional é (re)construída dentro da perspectiva socioconstrucionista do self (DUSZAK, 2002), por meio de uma prática discursiva que configura uma autoconstrução reflexiva sustentadora das relações de poder da ideologia patriarcal. Para tal, me apoio na epistemologia feminista (LYKKE, 2010), na Análise de Discurso Crítica (FAIRCLOUGH, 2001; RESENDE; RAMALHO, 2006, 2011) e na Linguística Sistêmico-funcional (HALLIDAY; HASAN, 1989; HALLIDAY, 1994), especificamente no Sistema de Avaliatividade (MARTIN, 2001; MARTIN; WHITE, 2005). Resultados revelam que quando o autor exprime suas opiniões, é o caráter avaliativo de suas escolhas lexicogramaticais que constroem os significados interpessoais que moldam e negociam as identidades em disputa, especialmente no que tange aos aspectos de (re)produção, distribuição e manutenção de ideologias de gêneros sociais através da (co)construção do self, configurando uma autoconstrução reflexiva.

Palavras-chave: Linguística Sistêmico-Funcional - Sistema de Avaliatividade Socioconstrução do self-Questões de gênero
\end{abstract}

\begin{abstract}
This study investigates how the hegemonic male identity (re)produced by a Brazilian comedian in a discursive event in traditional media is (re)constructed within the socio-constructive perspective of the self (DUSZAK, 2002), through a discursive practice that constitutes a self-reflexive supporting device of the patriarchal ideology power relations. The theoretical support for this investigation comes from Feminist Epistemology (LYKKE, 2010), Critical Discourse Analysis (FAIRCLOUGH, 2001, RESENDE; RAMALHO, 2006, 2011), and Systemic-Functional Linguistics (HALLIDAY; HASAN, 1989; HALLIDAY, 1994), specifically the Appraisal System (MARTIN, 2001; MARTIN; WHITE, 2005). The results reveal that when the author expresses his opinions, it is the evaluative character of his lexicogrammatical choices that construct the interpersonal meanings that shape and negotiate the identities in dispute, especially with respect to the aspects of (re)production, distribution and maintenance of gender related ideologies, through the (co)construction of the self, in a reflexive self-construction.
\end{abstract}

Keywords: Systemic-Functional Linguistics - Appraisal System - Socioconstruction of the self-gender issues 


\section{INTRODUÇÃO}

No cotidiano online da vida contemporânea em que adquirimos, trocamos e construímos conhecimento em tempo real por meio de experiências mediadas (GIDDENS, 2002), temos na internet a nossa maior fonte de informação. Com esse acesso, a fluidez entre os discursos que circulam dentro e fora da sala de aula traz à tona toda a complexidade do mundo "real" do lado de fora, nos convidando a incluir essas discussões no nosso dia a dia. Nesse cenário, este estudo apresenta um exemplo de análise de questões de interdiscursividade e construção identitária para um texto que circula na nova mídia, que pode ser trazido para a sala de aula para fomentar entendimentos acerca de questões de gênero e da necessidade de aprofundamento de nossa postura interpretativa ao lidarmos com qualquer conteúdo discursivo-textual.

Nesse sentido, analiso um post do Facebook ${ }^{\circledR}$ escrito em resposta a uma entrevista (anexo I) feita por um humorista brasileiro a atrizes americanas de uma série de TV internacional de audiência global ${ }^{1}$, repercutida quando as entrevistadas se construíram na prática identitária feminista (BUTLER, 1990) para apontar o que consideraram, em suas palavras, exemplos de misoginia. $\mathrm{O}$ autor da postagem, uma jovem celebridade do universo cibernético com mais de 2,5 milhões de fãs, se alinha ao humorista em uma tentativa de (re)construção de identidade que repreende o vasto apoio (anexo II) dado à atitude das atrizes. Nesse processo, o autor cria significados sociossemióticos (HALLIDAY 1994) por meio de suas escolhas no sistema de avaliatividade (MARTN, 2001; MARTIN; WHITE, 2005), para (re)construir a prática identitária masculina na dinâmica us-them de socioconstrução do self (DUSZAK, 2002), configurando autoconstruções reflexivas da identidade hegemônica (RESENDE; RAMALHO, 2006, 2011) patriarcal, como mostro a seguir.

\section{ARCABOUÇO TEÓRICO}

Para entender como o autor do texto analisado se constrói identitariamente na dinâmica us-them de Duzak (2002), adoto um olhar moldado pela epistemologia feminista interseccional

\footnotetext{
${ }^{1}$ A série em questão é Orange is The New Black, cujo elenco é majoritariamente feminino, com personagens de identidade de gênero, raça/etnia e classe social variadas, e trata da história de uma mulher Piper Chapaman, uma mulher de 30 anos que é condenada a quinze meses de prisão depois de ser condenada por um crime de dez anos de transportar dinheiro para sua namorada traficante de drogas". Na série conforme disponível na Internet Movie Data Base: http://www.imdb.com/title/tt2372162/?ref_=ttfc fc tt
} 
(LYKKE, 2010). Me atendo ao entendimento discursivo da socioconstrução de self, trago os preceitos da Análise de Discurso Crítica (FAIRCLOUGH, 2001, RESENDE; RAMALHO, 2006, 2011) e da Linguística Sistêmico-Funcional (HALLIDAY; HASAN, 1989; HALLIDAY, 1994), especialmente no Sistema de Avaliatividade (MARTIN, 2001; MARTIN; WHITE, 2005), para melhor entender as escolhas lexicogramaticais feitas pelo autor. A seguir, discuto os conceitos utilizados nesta análise, conforme preconizados por cada um dos campos acima.

\section{Epistemologia feminista}

A epistemologia feminista (LYKKE, 2010) prevê uma perspectiva de crítica a discursos hegemônicos relacionados ao gênero/sexo enquanto construto social ${ }^{2}$. Assim, ao adotar esse ponto de vista, adoto o "princípio do conhecimento situado" de HARAWAY (1991 apud LYKKE, 2010, p.5), que sugere uma possibilidade de análise feminista não universalista, ou seja, sem pretensões de criar uma "imagem de mundo neutra e objetiva" (HARAWAY, 1991 apud LYKKE, 2010, p.5) que maquiasse os fenômenos sociais como eventos livres da subjetividade situada, vinculada localmente à cada prática observada.

Com isso em mente, me atenho ao conceito de identidade de gênero como um construto do self pela linguagem (BUTLER, 1990) e, portanto, ao caráter performativo da identidade de gênero como prática de significação (BUTLER, 1990). A importância desse conceito advém do fato de entendermos então a identidade de gênero não mais como uma categoria a qual nos subscrevemos, mas como uma performance ativamente construída (BUTLER, 1990), que promove um equilíbrio entre agência individual e inequidade estrutural, exatamente como podemos observar na construção identitária das mulheres durante a entrevista (anexo I), o que foi constrangido pelo autor da postagem aqui analisada, ao apagar tais construções, buscando minimizá-las ou esvaziá-las de significado, como veremos em breve.

Quanto à identidade feminista e feminina, mantenho em mente o conceito de voz das mulheres (GAL, 1995, p.174), que presume essa "voz" como "a expressão pública de um exemplo particular de perspectiva de self e vida social, o esforço de representar a sua própria experiência ao invés de aceitar as representações de outros mais poderosos" (grifo meu) e

\footnotetext{
${ }^{2}$ Mas não somente, no caso de um olhar interseccional (COLLINS, 1990; COLLINS e BURGE, 2016)
} 
carrega consigo a ideia de uma "perspectiva posicionada" (GAL, 1995, p.174), em decorrência da consciência de gênero (GAL, 1995).

\section{Análise de Discurso Crítica (ADC)}

Com base no modelo tridimensional de análise de discurso crítica de Fairclough (2001), doravante $\mathrm{ADC}$, tomamos a centralidade do conceito de discurso da ADC como ponto inicial do entendimento da expressividade linguística que se dá no nível da instanciação do texto. $\mathrm{O}$ discurso como prática social se refere a "uma entidade intermediária, que se situa entre as estruturas sociais mais fixas e as ações individuais mais flexíveis" (RESENDE; RAMALHO, 2011, p.14). Nessa dinâmica "os eventos discursivos específicos variam em sua determinação estrutural segundo o domínio social particular ou o quadro institucional em que são gerados" (FAIRCLOUGH, 2001, p.91). Entre essas duas dimensões (a prática social e o evento discursivo) estão as práticas discursivas (FAIRCLOUGH, 2001), que correspondem a instâncias de produção, distribuição e consumo dos textos que estão em circulação.

Um conceito especialmente importante nesse cenário é o de autoconstrução reflexiva (RESENDE; RAMALHO, 2006, p.45), que se refere à construção que fazemos nós mesmos “em revisões da reflexividade institucional" (RESENDE; RAMALHO, 2006, p.45), ou seja, à luz da reflexão imposta pela hegemonia institucionalizada por meio das "experiências mediadas" (RESENDE; RAMALHO, 2006, p.45) do nosso cotidiano moderno, em que somos metralhados por conhecimento e informação, independente de nossas vontades. Assim, temos na autoconstrução reflexiva uma poderosa ferramenta a serviço da agenda ideológica, já que a influência das informações circundantes pode gerar essas autoconstruções por meio das "formas simbólicas próprias de uma atividade social particular" (RESENDE; RAMALHO, 2006, p.45).

\section{Linguística Sistêmico-funcional}

A linguística sistêmico-funcional (doravante LSF) vê a linguagem como um sistema semiótico de troca de significados (HALLIDAY, 1994) e tem seu foco na escolha paradigmática do falante, que constrói seus significados não só por aquilo que opta por usar, mas também por aquilo que escolhe deixar de fora. Um conceito chave da LSF é o que se refere ao texto como 
uma instanciação do sistema de metafunções semânticas por meio das escolhas lexicogramaticais feitas pelo falante (HALLIDAY, 1994). Assim, parte-se de parâmetros criados na esfera extralinguística: o contexto de cultura, onde se constrói o gênero discursivo, e o contexto de situação, onde o texto se encontra em relação ao campo (o que está ali representado), às relações (quem ali se relaciona) e ao modo (qual organização simbólica é utilizada ali) (HALLIDAY; HASAN, 1989). Na esfera linguística, o texto é realizado em sua materialidade discursiva (FOUCAULT, 1972) pelo uso da linguagem no nível do conteúdo semântico e lexicogramatical (HALLIDAY; HASAN, 1989). Nesse sentido, o texto é a realização das metafunções ideacional (entender o meio ambiente), interpessoal (agir sobre os outros) e textual, que dá relevância às outras duas (HALLIDAY, 1994).

"Na linguística sistêmico-funcional, a análise do discurso interage com a análise da gramática e análise da atividade social, em algum lugar entre o trabalho de gramáticos por um lado e dos teóricos sociais do outro" (MARTIN; ROSE, 2003, p.4). Assim, a gramática sistêmico-funcional de Halliday (1994) se dispõe a "quebrar o código" (HALLIDAY, 1994, p.F56) das escolhas sociossemióticas em um "propósito de análise textual” (HALLIDAY, 1994, p.F41) “interpretativa” (HALLIDAY, 1994, p.F42.). Para melhor compreensão, a linguagem é dividida em três estratos que são as realizações dos contextos de cultura e situação: a grafologia/fonologia; a lexicogramática e a semântica do discurso.

Este trabalho busca entender as escolhas feitas na materialidade discursiva do texto analisado, em consonância com as outras instâncias discursivas aqui esplanadas. Como a semântica do discurso consiste de um total de seis sistemas, interconectados e interdependentes, como ocorre similarmente nos outros níveis dos estratos (MARTIN; ROSE, 2003), separamos esses sistemas (somente par afins de análise) em: i) ideação; ii) conjunção; iii) identificação; iv) periodicidade; v) negociação; vi) avaliatividade (MARTIN; ROSE, 2003).

Como veremos a seguir, opto por focar no sistema de avaliatividade pois ele nos permite entender as escolhas acerca de como o autor se sente ao fazer sentido de si no mundo / com o mundo. 


\section{Sistema de Avaliatividade}

O sistema de avaliatividade é por onde fazemos nossas escolhas no nível da "semântica de avaliação" (MARTIN, 2001), ou seja, é o sistema utilizado para demonstração de "como os interlocutores estão sentindo suas experiências, os julgamentos que fazem e o valor que colocam nos vários fenômenos que experienciam" (MARTIN, 2001, p.144), Assim, as “escolhas lexicogramaticais nessa área são vistas como construtos (expressam significados ao mesmo tempo que os criam) de uma pequena variação de categorias gerais de reação" (MARTIN, 2001, p.142). Além disso, o sistema de avaliatividade é usado em combinação com o sistema de negociação e envolvimento (MARTIN; WHITE, 2005), aos quais não me atenho neste trabalho.

Dentro do sistema de avaliatividade, observei as categorias das escolhas lexicais enquanto construtos de avaliatividade nos três campos da atitude: afeto, julgamento e apreciação, aspectos da avaliação que são conectados com dois importantes sistemas de construção de significado: engajamento e gradação (MARTIN, 2001).

Por afeto, entendemos tudo aquilo que diz respeito à relação do sujeito com o mundo, de dentro para a fora, configurando "o sistema básico” (MARTIN, 2001, p.147) que é institucionalizado no nível da ética e da estética. Para entender esse campo atitudinal, vemos escolhas, positivas ou negativas, relacionadas a emoções que envolvem "questões do coração" tristeza, ódio, felicidade, amor; ou de "bem estar ecossocial" - ansiedade, medo, confiança; ou de "telos (o alcance de objetivos)" - tédio, (des)prazer, curiosidade, (des)respeito ${ }^{3}$.

No nível da ética, isto se dá por meio do julgamento como "uma matriz de avaliação para o comportamento" (MARTIN, 2001, p.147), feito na esfera da estima social, quando baseado em o quão (a)normal, (in)capaz ou (não) confiável algo/a forma com que alguém age é, e da sanção social, quando sua base é determinada pelo quão (ir)repreensível ou (des)honesto essa dada coisa/ situação /pessoa é/ age.

No nível da estética, o afeto como apreciação se mostra nas escolhas feitas com base na reação que algo/alguém gera no âmbito do impacto (o quanto cativou) ou da qualidade (o quão bom/ruim é; ou com base na composição por equilíbrio (como se mantém) ou complexidade (se é difícil de acompanhar); ou com base na valoração (se vale à pena) (MARTIN; WHITE, 2005).

\footnotetext{
${ }^{3}$ Não devemos limitar os sentimentos a esses, mas esses são exemplos dessas esferas de significado.
} 
Em conjunto com a avaliatividade (MARTIN; WHITE, 2005), o falante faz escolhas relacionadas ao engajamento (MARTIN; WHITE, 2005), que visam estreitar ou alargar as relações de solidariedade do seu interlocutor para com os significados propostos no texto em si (MARTIN; WHITE, 2005) e seu desenvolvimento no encadeamento de ideias. Além disso, a gradação auxilia na amplificação do efeito (MARTIN; WHITE, 2005) das qualidades e processos no que tange à força e ao foco (MARTIN; WHITE, 2005) do que constroem.

\section{Sócio-construção do $S E L F$}

Com base na análise textual instrumentada pela LSF e o Sistema de Avaliatividade, a construção da identidade pela sócio-construção do self é observada com base na premissa de que "somente ao nos comparar com os outros podemos construir nossas afiliações e nãoalinhamentos" (DUSZAK, 2002) de pensamentos e disposições ideológicas, culturais e estéticas, podemos dizer que é na relação nós-outros (ou nós-eles/as) que construímos e desempenhamos nossa identidade. Por meio dessas relações de ingroupness e outgroupness (DUSZAK, 2002) nos moldamos em uma relação dialética excludente e constitutiva entre aquilo que construímos como intragrupo ${ }^{4}$ (DUSZAK, 2002), referente ao que é inerente ao nosso grupo, dentro do qual circundamos nossa identidade, e aquilo que construímos como extragrupo ${ }^{5}$ (DUSZAK, 2002), tudo aquilo ao qual nos opomos, abertamente ou por inferência, por não ser incluído nas características e posturas desejáveis ou coerentes com a nossa identidade intragrupo.

Vale marcar que podemos "desenhar, revisar e equilibrar as fronteiras entre os grupos" (DUSZAK, 2002, p.2) sempre que oportuno. Assim, ao moldar nossas identidades por esses parâmetros, criamos relações de proximidade ou desapego (DUSZAK, 2002), para com o outro e seus valores. Por meio de "estratégias linguísticas, culturais e sociais" (DUSZAK, 2002, p.8), construímos o intragrupo no "autoelogio, autoengrandecimento e autoexaltação" (DUSZAK, 2002, p.8) e, ao mesmo tempo, construímos o extragrupo negativamente, por estratégias de “condescendência, invalidação, marginalização e coletivização do outro" (DUSZAK, 2002, p.8).

Esse arcabouço teórico é um importante balizador para a análise da materialidade discursiva (FOUCAULT, 1972) do texto aqui investigado, pois na sócio-construção do self

\footnotetext{
${ }^{4}$ Tradução livre minha para in-group.

${ }^{5}$ Tradução livre minha para out-group.
} 
(DUSZAK, 2002) construímos a nossa identidade em uma relação sine qua non de co-construção da identidade do outro (DUSZAK, 2002). Nesse contexto, se é nas nossas escolhas léxicogramaticais que realizamos o nível do conteúdo semântico (HALLIDAY, 1989) pelas metafunções do sistema semiótico da linguagem (HALLIDAY, 1994), é viabilizando nessas escolhas a expressão de nossos sentimentos de afeto, julgamento e apreciação do outro ou daquilo que ele produz (MARTIN, 2001) que construímos nossos posicionamentos e afiliações.

Assim, idealmente, temos na "agência, escolha e voz" (BUTLER, 1990, p.6) do indivíduo enquanto construto dos grupos aos quais se afiliam (DUSZAK, 2002), o poder de transformar as práticas sociais (FAIRCLOUGH, 2001), no sentido de (re)construir as identidades de gênero nas práticas discursivas (FAIRCLOUGH, 2001). Nesse cenário, o viés emancipatório da linguagem na função de mediadora entre o indivíduo e as práticas hegemônicas culturais (BUTLER,1990) pode ser visto como uma forma de mitigar as relações assimétricas de poder (FOUCAULT, 1972), como se propuseram a fazer as atrizes na entrevista que suscitou a postagem de Facebook ${ }^{\circledR}$ que aqui analiso. Por outro lado, as práticas discursivas (FAIRCLOUGH, 2001) podem corroborar com a manutenção e reprodução da identidade hegemônica patriarcal enquanto prática de significação (BUTLER, 1990), por meio de autoconstruções reflexivas (RESENDE; RAMALHO, 2006, 2011), como fez o autor ao construir sua identidade por afiliação ingroupsness (DUSZAK, 2002), com o humorista/entrevistador e outgroupness, com as atrizes entrevistadas/público que lhe apoia.

\section{METODOLOGIA}

Posicionada teoricamente, a escolha do texto desta análise se deu pelos seguintes critérios: o texto deveria ser um evento discursivo (FAIRCLOUGH, 2001) que respondesse ao acontecimento (FOUCAULT, 1972) da entrevista entre o humorista Rafael Cortez e as atrizes da série Orange Is The New Black (OITNB) - vide anexo I, por convergência da nova mídia (VAN DIJK, 2006). Desse modo, postagens em sites de serviço de rede social, de comportamento/estilo de vida e de notícias, internacionais e nacionais, foram investigados.

Durante o levantamento feito, uma postagem no Facebook ${ }^{\circledR}$ chamou a atenção pois o autor a produziu com o intuito de defender o humorista do rechaçamento que seu trabalho vinha sofrendo nas práticas discursivas (FAIRCLOUGH, 2001) relacionadas ao evento, que enalteciam 
a atitude das atrizes ao não se calarem diante do que consideraram inapropriado (anexo II). O intrigante desse texto era exatamente tentar entender sob que perspectiva Felipe (o autor da postagem) expõe o seu ponto de vista em defesa de Rafael (o entrevistador).

Assim, foi feito um levantamento das escolhas paradigmáticas lexicogramaticais (HALLIDAY, 1994) dos elementos de avaliatividade (MARTIN, 2001; MARTIN; WHITE, 2005) utilizados por Felipe para fins de criação de significados atitudinais (MARTIN, 2001) e sócio-construção do self no eixo de construção de identidade nós-eles (DUSZAK, 2002). Nessa construção de ingroupness e outgroupness (DUSZAK, 2002), o autor da postagem explica, justifica e naturaliza (RESENDE; RAMALHO, 2006) o comportamento característico da identidade hegemônica de gênero, caracterizando uma autoconstrução reflexiva (RESENDE; RAMALHO, 2006) dessa identidade masculina hegemônica.

\section{Contextualização da Análise}

O texto analisado é uma postagem feita no site de serviços de rede social Facebook® por um homem de 27 anos que se descreve como empresário, vlogger, ator e escritor brasileiro. Com, mais de 2,5 milhões de fãs no momento, Felipe Neto é uma celebridade construída na nova mídia (VAN DIJK, 2006) e é considerado um formador de opinião contemporâneo entre jovens, com influência em instâncias da mídia tradicional e independente.

Felipe postou o texto no dia 19 de junho de 2015, às 18:06, contando duas semanas depois com mais de 6.800 curtidas e mais de 160 compartilhamentos. A postagem foi escrita em resposta a um acontecimento (FOUCAULT, 1972) dado por um evento discursivo (FAIRCLOUGH, 2001) de considerável repercussão.

O evento discursivo (FAIRCLOUGH, 2001) que gerou o acontecimento (FOUCAULT, 1972) é uma entrevista concedida por três atrizes americanas a um humorista brasileiro do programa CQC®, programa de auditório jornalístico/humorístico exibido no canal Bandeirantes ${ }^{\circledR}$ de televisão aberta. Uzo Aduba, Natasha Lyonne e Samira Wiley são protagonistas da série "Orange is The New Black" (OITNB), cuja trama se dá em torno do dia a dia de presidiárias no sistema carcerário americano. A série, conhecida por seu viés feminista, é produzida e veiculada pelo canal online e aplicativo NetFlix ${ }^{\circledR}$, que a promoveu no Brasil. Primeiramente no canal aberto, a entrevista aconteceu no dia 15 de junho, mas o vídeo ganhou repercussão internacional 
quando replicado no site YouTube ${ }^{\circledR}$ (mais de 650mil acessos até julho de 2015). O humorista escalado para fazer a entrevista foi Rafael Cortez, homem de 32 anos, conhecido no Brasil por fazer entrevistas com celebridades.

\author{
ANÁLISE \\ Os trechos analisados estarão dispostos antes da análise, como segue. \\ O caso do Rafael Cortez e a entrevista do CQC com as atrizes \\ de Orange Is The New Black é mais um caso de burrice e \\ péssima análise de parte do público.
}

Excerto 1 - primeiro parágrafo do post

Nesse primeiro parágrafo, o autor apresenta sua avaliação sobre o acontecimento (FOUCAULT, 1972) focando no público que repercutiu negativamente o evento discursivo (FAIRCLOGH, 2001). Para tal, ele usa uma avaliação negativa altamente graduada (MARTIN; WHITE, 2005) para avaliar a análise feita por esse público ("péssima análise"), o que pode ser entendido como uma crítica ao público, com a escolha lexical na esfera da estima social do julgamento de sua capacidade (MARTIN, 2001) ou ainda, na esfera da apreciação, como uma escolha que agrega valoração negativa à análise em si, enquanto produto (MARTIN; WHITE, 2005). De qualquer forma, fica claro o seu descontentamento com o posicionamento daqueles que apoiaram a atitude das entrevistadas quando faz mais uma avaliação, agora na esfera do afeto, indicando a "burrice" como atributo negativo do público (MARTIN; WHITE, 2005).

Em outras palavras, podemos inferir que para o autor o público é burro e incapaz de fazer análise, por estima social (capacidade) e sanção social (propriedade/o que fez é repreensível) (MARTIN, 2001), já que sua análise está muito mal composta, em avaliação por apreciação negativa de composição, (MARTIN; WHITE, 2005), tornando improcedentes as críticas sofridas pelo entrevistador, portanto. Além disso, o token de apreciação implícita (MARTIN; WHITE, 2005) "mais" em "mais um caso", designando impacto de reação (MARTIN; WHITE, 2005), demonstra a impaciência do autor para com esse mesmo público, nos levando a crer que não é a primeira vez que isso acontece: o público errou de novo; o público tem errado.

Através de suas escolhas avaliativas até aqui, Felipe constrói sua identidade na sua posição de sujeito com expertise por dois vieses: o primeiro, na demonstração de conhecimento 
histórico do tipo de caso com o qual vai lidar ("este é mais um desses casos em que o público erra"), e o segundo, o outro (DUSZAK, 2002) do primeiro, na construção da identidade do público como constantemente burro e incapaz de fazer análise, já que mais uma vez ele se comporta assim. Dessa forma, sob a dinâmica us-them (DUSZAK, 2002) temos o autor expert de um lado, em oposicão ao público burro e incapaz do outro.

Antes de mais nada, quero deixar claro que o Rafael é um
amigo, alguém que admiro, um cara de inteligência
diferenciada e incrível capacidade artística (pra quem não
conhece, procure saber o que esse cara faz com um violão, por
exemplo).
Excerto 2 - Segundo parágrafo do post

No segundo paragrafo, o autor começa então a elencar uma série de qualidades do Rafael ("um amigo, alguém que admiro, um cara de inteligência diferenciada e incrível capacidade artística"), indicando na esfera do afeto, a qualidade positiva do atributo "amigo" e na alta gradação do atributo (MARTIN; WHITE, 2005) "de inteligência diferenciada" e "(de) incrível capacidade artística", que também se traduzem na estima social positiva criada pela ideia da alta capacidade (MARTIN, 2001) do humorista. Corroborando com essa alta capacidade artística, a apreciação de valoração positiva em "o que esse cara faz com o violão" (MARTIN; WHITE, 2005) expõe um julgamento implícito de estima social por capacidade (MARTIN, 2001), no sentido de que Rafael é capaz, Rafael tem talento.

Ainda nesse trecho do texto, Felipe Neto constrói a identidade do Rafael como amigo e, portanto, em uma relação de ingroupness (DUSZAK, 2002) com o autor. O Rafael, na terceira pessoa, apto a ser julgado (DUSZAK, 2002), é julgado de maneira enaltecedora e engrandecedora, como sendo admirável, muito inteligente e incrivelmente talentoso.

Contudo, Rafael teve um dia infeliz. Um dia em que fez uma entrevista que ficou, fundamentalmente, ruim. As perguntas não funcionaram, a ideia foi fraca, a execução conseguiu ser pior devido à sua dificuldade com 0 inglês e, como resultado, acabou saindo um trabalho muito abaixo do potencial dele. Um belo exemplo de como a matéria foi mal pensada foi a pergunta da "Suzane Von Richthofen", será que nenhum roteirista previu que as atrizes ficariam com cara de "que merda é essa? 
Esse cara quer escalar uma atriz brasileira pro elenco?"... Enfim, acontece!

Excerto 3 - Terceiro parágrafo do post

No terceiro parágrafo, Felipe não fala de Rafael, mas de uma série de circunstâncias que levaram Rafael a "viver o que viveu", em oposição a "fazer o que fez". Desse modo, o autor marca a falta de agência do humorista, ao não focar nele, mas nas perguntas (que não funcionaram), na ideia (que foi fraca), na execução (que foi ruim), no seu inglês (que se mostrou pobre para o nível de dificuldade, que era alto), no trabalho em si (que ficou aquém do potencial de Rafael) e na matéria (que foi mal pensada). Mais ainda, Felipe classifica a entrevista como ruim em seu fundamento ("fundamentalmente ruim"), o que também serve para eximir Rafael de culpa, uma vez que a falha supostamente teria vindo do material. Assim, tudo não passa de efeitos da casualidade da vida.

É muito interessante como Felipe não dá à Rafael agência nem sobre a execução da entrevista, realizada em sua materialidade pelo humorista, pois a trata como ruim devido a questões imateriais como "saber inglês o suficiente". Nesse ponto, erra o autor ao resumir o insucesso da interação ao domínio do código (inglês), já que apaga a existência de outras "habilidades humanas que engajam em padrões recíprocos de comunicação e aproximam ou distanciam os falantes na interação" (DUSZAK, 2002, p.1) como "questões de afiliação quanto à identidade, gênero, posicionamento politico, entre outros" (DUSZAK, 2002, p.1).

Por fim, concluo por inferência que Felipe quer que assimilemos que Rafael tem potencial mais alto do que o demonstrado nesse fatídico dia que viveu e que a falha da entrevista se deve à ela mesma, um todo formado de partes falhas, gerando a subsequente insatisfação do público, pela qual Rafael não pode ser responsabilizado. Para sustentar e reforçar esse ponto de vista, o autor menciona então mais dois participantes, prováveis culpados por tal fracasso: o roteirista (que não previu a reação das atrizes) e, em última instância, as próprias atrizes (que não entenderam as perguntas ou as ideias, por uma questão de código mal executado).

Em termos de construção de identidade, Rafael é agora, portanto, a vítima de uma fatalidade, alguém como nós, que está sujeito aos desmandos da vida. Assim, a construção de ingroupness (DUSZAK, 2002) por afiliação entre leitor, Rafael, e o autor, Felipe, começa a ganhar corpo. Nesse contexto, Felipe separa dois tipos de leitores/as-público que lhe interessa: o 
out-group (DUSZAK, 2002) dos que "não sabem o que falam" ou "não entenderam o que houve" (as atrizes e o público que as apoiou) e o in-group dos que "conhecem bem o que acontece" na vida e, agora, através de seu relato, “conhecem bem quem é Rafael”, fazendo sua avaliação sobre o público no campo da propriedade, em julgamento de sanção social (MARTIN, 2001), por inferência, determinando quem pode ou não julgar Rafael.

\section{O que mais me surpreende nisso tudo? A Direção do CQC (que também é feita por um amigo, o Diego Pignataro) ter permitido a matéria ir ao ar, prejudicando a imagem do Rafael e a imagem do próprio programa. \\ Excerto 4 - Quarto parágrafo do post}

Agora no quarto parágrafo, Felipe segue (re)construindo as duas identidades que vem clamando para si: a de expert por conhecimento das pessoas envolvidas, já que é amigo do Rafael e amigo agora do diretor, e a de expert por conhecimento de causa, uma vez que conhece bem esse tipo de situação/ casos como esse e, agora, se pode deduzir o conhecimento também da direção, já que provavelmente conhece o trabalho do amigo.

É interessante marcar que a informação sobre a amizade de Felipe Neto com Diego Pignataro, na esfera do afeto, nos leva a entender que ele se posiciona ao lado do amigo por ingroupness de amizade e vai, assim, julgar não o Diego em si, mas o seu trabalho: a direção por ele feita. Nesse cenário, Felipe escolhe usar "prejudicar" para falar do que foi feito, o que avaliza a apreciação negativa de impacto (MARTIN; WHITE, 2005), que ele significa com a escolha do léxico "a imagem” ao se referir a Rafael e ao programa. Ou seja, ele não é categórico em implicar sanção ou estima social propriamente, pois ameniza sua crítica ao colocá-la no campo da estética, implicando não ter valido à pena - apreciação valorativa negativa (MARTIN; WHITE, 2005) ter colocado no ar tal "matéria mal pensada" - apreciação compositiva negativa (MARTIN; WHITE, 2005) - para o programa em si, mas não pessoalmente para Diego.

Mas_aí vem_o que me irrita nisso tudo. Ao invés do resultado ter sido "essa matéria ficou uma merda", a polêmica pública e maioria dos compartilhamentos foi em função de "essa matéria ficou machista", porque Rafael salientou a beleza das atrizes e perguntou se era difícil tanta mulher junta atuar com TPM.

Excerto 5 - Quinto parágrafo do post 
No parágrafo seguinte, fica claro que no entendimento do autor a avaliação do evento discursivo (FAIRCLOUGH, 2001) deveria ter permanecido no campo da apreciação estética, com as pessoas exprimindo sua opinião sobre o trabalho que foi feito, o produto "matéria", "entrevista", e que nesse campo, sim, pode-se usar do afeto negativo altamente graduado ("uma merda") (MARTIN; WHITE, 2005). Também, as escolhas de Felipe quanto aos vieses ético e estético de sua avaliação (MARTIN; WHITE, 2005) do acontecimento (FOUCAULT, 1972) ficam claras quando ele diz que "essa matéria ficou uma merda" (estético) e "machista" (ético).

Ao explicar de maneira simplista o porquê de a polêmica ter acontecido, ao falar que o humorista apenas visou "salientar a beleza das atrizes", driblando a explicação detalhada do quê e como Rafael disse o que disse, Felipe minimiza a ação do humorista. A pergunta "se era tão difícil tanta mulher junta atuar com TPM" também corrobora com a minimização dos dois feitos por não entrar na questão comportamental de Rafael, no incômodo gerado e na indignação com que as mulheres perceberam tal comportamento. De qualquer forma, é interessante ver como Felipe não percebe que sua explicação já denota instanciações da formação discursiva (FOUCAULT, 1972) machista, através da padronização (THOMPSON, 1995 apud RESENDE; RAMALHO, 2006, p.27-28) do comportamento feminino por questões relacionadas à sua menstruação, característica tão feminina quanto secundária em qualquer ambiente de trabalho.

Caralho galera, pelo amor de Deus! Está ficando cada dia mais
difícil, para não dizer impossível, fazer humor no Brasil. Vamos
parar de confundir piada ruim com piada preconceituosa e
focar no que realmente é preconceituoso. Vamos lutar contra
Bolsonaros e Malafaias da vida, pois esses sim atrasam a nossa
sociedade, não um humorista que teve UM dia ruim no meio de
800 dias bons. Excerto 6 - Sexto parágrafo do post

Felipe, então (excerto 6), demonstra seu descontentamento com algo mais amplo: a dificuldade de se fazer humor no Brasil ("está ficando cada dia mais difícil, para não dizer impossível, fazer humor no Brasil”). O autor enfatiza na alta gradação de intensificação por repetição ("mais difícil", "impossível”) a sua avaliação por meio da apreciação de reação negativa (MARTIN; WHITE, 2005) quanto ao ato de "fazer humor no Brasil", implicando julgamento por estima social (MARTIN, 2001), já que nos passa a impressão de que isso foge dos parâmetros de normalidade ("está ficando" em oposição ao que "é” ou "era"). 
Isto fica evidente logo adiante quando ele baseia sua avaliação do evento discursivo no que ele classifica como uma separação entre "piada ruim", avaliada sob a perspectiva estética de apreciação negativa em sua composição e reação de impacto e qualidade (MARTIN; WHITE, 2005), e "piada preconceituosa", aquela que deve ser sancionada socialmente por ser julgada no campo da propriedade, estando sujeita à repreensão (MARTIN; WHITE, 2005). O que Felipe parece não perceber é que essa distinção, mesmo correta em várias instâncias, não procede nesse caso. Dentro da formação discursiva (FOUCAULT, 1972) do feminismo, a avaliação apreciativa negativa da piada "mal feita", "mal composta", ou "ruim", e avaliação de sanção social (MARTIN, 2001) por repressão por machismo existem em uma relação constitutiva e reflexiva, pois do ponto de vista das atrizes as piadas foram ruins exatamente por serem de cunho misógino, como explicitamente verbalizado por elas e por quem repercutiu o acontecimento (FOUCAULT, 1972).

$\mathrm{O}$ autor se reposiciona na tentativa de absorver o/a leitor/a para o seu intragrupo (DUSZAK, 2002) por meio de um convite à mudança de avaliação que abarque uma mesma identidade nós (DUSZAK, 2002), construída por afiliação à sociedade, que quer o melhor na luta contra o "verdadeiro" preconceito. Ou seja, temos agora "todos nós" contra o "verdadeiro" extragrupo (DUSZAK, 2002): “eles”, os "Bolsonaros e Malafaias da vida”, construído através da avaliação por julgamento de estima social negativa no campo da tenacidade (MARTIN, 2001), que implica serem eles os que não merecem nossa confiança. Nesse sentido, no viés da veracidade, Felipe incorpora o "sim" em "pois esses sim atrasam a nossa sociedade", um token de julgamento por sanção social (MARTIN, 2001), identificando aqueles que devemos verdadeiramente lutar contra, por serem verdadeiramente perigosos. Dessa forma, mais uma vez surge o caráter circunstancial da entrevista na vida de Rafael Cortez e a eliminação se sua agência no evento como "um humorista que teve um dia ruim no meio de 800 dias bons".

$\mathrm{Na}$ construção dessa nova identidade para nós, os/as leitores/as, juntamente com o autor e seus amigos, Rafael e Diego, Felipe opta pela escolha da primeira pessoa do plural "vamos" para incitar-nos a dividir com ele valores éticos e morais, valores agora "nossos", da "nossa sociedade", que por dedução excluem o apontamento de situações de machismo em atos humorísticos aprovados pelo senso comum. É realmente fascinante como o autor mina a resistência (FAIRCLOUGH, 2001) construída pelo posicionamento adotado pelas mulheres na entrevista, clamando exatamente pelo abandono do que ele vê como uma causa menor, 
simbolizada, para ele, pelo julgamento equivocado feito por mulheres que não entenderam a dinâmica do evento discursivo em questão, e o público que as apoiaram, burro e incapaz de fazer uma análise correta do que deveria ser apenas um momento de interpretação e avaliação de fatores de cunho estético. Ao trazer o/a leitor/a para o seu lado agora, ele quer diferenciar tal leitor/a desse outro grupo incompetente, ignorante e equivocado, para o seu grupo dos que sabem o que realmente importa.

Seguindo na lógica de sua percepção de construção identitária na dinâmica nós-eles/as (DUSZAK, 2002), agora com o/a leitor/a posicionado como membro do intra-grupo (DUSZAK, 2002) da "sociedade que se importa com o que merece", no parágrafo seguinte, Felipe demonstra seu descontentamento na esfera do afeto (MARTIN; WHITE, 2005), representado pelo desiderativo negativo "infelizmente", seguido pela constatação de que nós, enquanto sociedade, estamos pendendo para o lado "dos que criticam sem ter propriedade" e perdendo o foco dos "Bolsonaros e Malafaias" para focar em quem "não merece", como seu amigo "humorista que teve um dia ruim no meio de 800 dias bons".

Infelizmente no Brasil estamos cada vez mais tendendo para esse lado. [Quando alguém comete um erro, acaba se tornando o inimigo da nação. Quando comete 500 acertos, é apenas mais um. Até hoje tentam caçar twittadas minhas de 2008 para achar algo machista (coisa que já fui bastante, sem saber) só para causar merda com a minha imagem nas mídias sociais. $\mathbf{E}$ assim é com inúmeros comunicadores]

Excerto 7 - Sétimo parágrafo do post

Felipe, assim (excerto 7), se constrói na narrativa como aquele que sabe do que essas pessoas que acusam outras de machistas são capazes: "até hoje tentam caçar twittadas minhas de 2008 para achar algo machista (coisa que já fui bastante, sem saber) só para causar merda com a minha imagem nas mídias sociais. E assim é com inúmeros comunicadores”. Fica claro então que aqueles que não concordam ter havido machismo na troca são agora vítimas de um sistema que privilegia a inconsequência, já que permite que aqueles que se afiliam ao outro, as feministas, "cacem informações" somente com o intuito de "causar merda" com sua "imagem nas mídias sociais". Nesse sentido, o outro feminista não é incorporado ao intragrupo, ficando relegado ao extragrupo, junto ao "verdadeiro" problema, "os Bolsonaros e Malafaias", cujas causas, paradoxalmente, representam tudo contra o qual o feminismo luta (observação empírica). 
Essa construção das/os feministas como tão opressoras quanto àqueles que julgam oprimi-las é parte integral da formação discursiva (FOUCAULT, 1972) do machismo, já que promove um apagamento da assimetria de poder (FOUCAULT, 1972) nas questões de gênero.

E aí [você] sabe o que vai acontecer? Vamos voltar para os tempos em que ninguém dava opinião e todo mundo se comportava como Luciano Huck, sorrindo pra câmera e sempre em cima do muro.

Excerto 8-Oitavo parágrafo do post

No parágrafo seguinte (excerto 8), Felipe pergunta diretamente ao/a leitor/a sobre sua expectativa a respeito do que acontecerá em consequência desse movimento de caça a humoristas machistas e traz logo a resposta demonstrando reconhecer esse leitor como parte de seu ingroup (DUSZAK, 2002) por meio da escolha da $1^{\text {a }}$ pessoa do plural para responder sua própria pergunta (DUSZAK, 2002). Agora com o/a leitor/a ao seu lado, Felipe não acha necessário explicitar exatamente o que quer dizer com "voltar para os tempos em que ninguém dava opinião e todo mundo se comportava como Luciano Huck". Apesar de ele explicar o que esse comportamento seria, quando em tese, "todo mundo" ficava "sorrindo para a câmera e sempre em cima do muro", aquele/a leitor/a que não se encontra alinhado com o autor pode não entender como uma atitude tão livre e democrática quanto a de usar sua agência para se posicionar quando se sente oprimido e desrespeitado pode ser comparada aos tempos de supressão de opinião. Assim, se por supressão de opinião podemos entender censura, através das relações de interdiscurso (RESENDE; RAMALHO, 2006, 2011), para entender o sentido deslocado de censura usado por Felipe é preciso estar bem identificado com ele, já que do contrário, o argumento parece falho e distante da realidade.

Precisamos do Rafael Cortez, do Rafinha, do Danilo e de todos os demais. Terão(sic) dias em que farão piadas merdas, em outros farão piadas boas. Mas desde que mantenham-se na arte de FAZER HUMOR, vamos parar com esse chilique mal direcionado e focar em quem realmente fode com tudo, pois esses sim comandam multidões com discursos de ódio.

Espero que [vocês] entendam.

Excerto 9 - Nono e décimo (últimos) parágrafos do post 
Por fim, como vemos acima (excerto 9), Felipe julga a manifestação das entrevistadas e seus apoiadores por sanção social por propriedade (altamente repreensível) (MARTIN, 2001) ("vamos parar com esse chilique mal direcionado"), inferindo o descontrole emocional daquelas que se posicionaram contra o que perceberam como misoginia ("chilique"). Ele reclama o foco naquilo que ele configura como "causa maior" ("quem realmente fode com tudo"), por sanção social positiva de veracidade (MARTIN, 2001) exprimida no "sim" em "esses, sim comandam multidões com discurso de ódio". O uso da expressão "discurso de ódio" chama a atenção pois é colocado como um construto do outro, do que não entende humor, tirando mais uma vez a agência dos humoristas, dessa vez os isentando de responsabilidade político-social.

A reação das entrevistadas ao não aceitarem o que consideraram escárnio e se posicionarem em um lugar de resistência e de luta contra esse status quo configura uma luta emancipatória (FAIRCLOUGH, 2001) e no entanto é classificada pelo autor como "chilique", em uma escolha na esfera do afeto que qualificaria esse atributo negativamente no viés da insatisfação e descontentamento (MARTIN; WHITE, 2005) fazendo ainda uma avaliação negativa de julgamento no âmbito da estima social, por anormalidade comportamental e por sanção social, por ser altamente repreensível (MARTIN, 2001).

Em consequência, a nova configuração nós-eles/as termina estabelecendo de um lado "o/a leitor/a instruído por ele/ o autor/ Rafael/ os humoristas/ a sociedade brasileira que quer o bem/ vítimas do feminismo e da censura" contra "Bolsonaros/Malafaias/feministas chiliquentas que caçam machismo em qualquer lugar/ público burro que não sabe fazer análise”, usando a sócioconstrução do self (DUSZAK, 2002) para moldar as identidades dos dois grupos opostos através de suas escolhas na esfera da avaliatividade (MARTIN, 2001) para configurar uma autoconstrução reflexiva (RESENDE; RAMALHO, 2006) da identidade hegemônica (FAIRCLOUGH, 2001) patriarcal.

\section{CONSIDERAÇÕES FINAIS}

Felipe se constrói como expert, pois conhece: uma análise errônea (do público incapaz e burro); o humorista Rafael Cortez (amigo talentoso); a direção do CQC (por conhecer o diretor); o machismo (quando ocorre ou não e como opera), o feminismo (como deve se portar e pelo que se vale a pena lutar), o humor (o que faz/como/porque algo é engraçado) e os verdadeiros 
problemas do Brasil (os Bolsonaros, os Malafaias, a censura). Assim, ao desenhar sua construção identitária no outro das atrizes, um outro antifeminista, não solidário à mudança do status hegemônico da ideologia referente ao gênero social e sem consciência de seu amplo alcance nas práticas discursivas e sociais (FAIRCLOUGH, 2001), deliberadamente ou não, o autor alinha seu discurso à formação discursiva do machismo, em uma relação interdiscursiva que corrobora com a autoconstrução reflexiva da hegemonia patriarcal, ressaltando a importância de subvertermos, via discurso, as relações de poder assimétricas (RESENDE e RAMALHO, 2006, 2011) nas questões de gênero.

\section{REFERÊNCIAS}

BUTLER, Judith. Gender trouble: feminism e the subversion of identity. London/New York: Routledge, Chapman e Hall, 1990.

DUSZAK, Anna. Us e others. Social identities across languages, discourses e cultures. (Introdução). Amsterdam/Philadelphia: John Benjamins, 2002.

FOUCAULT, Michel. The archeology of knowledge. New York: Pantheon Publications, 1972.

FAIRCLOUGH, Norman. Discurso e Mudança Social. Brasília: Editora Universidade de Brasília, 2001.

GAL, Susan. Language, gender e power: an anthopological review. In: Hall e Bucholtz (Ed.), Gender articulated: socially constructed self. New York: Routledge, 1995.

GIDDENS, Anthony. Modernidade e identidade. Rio de Janeiro: Jorge Zahar, 2002.

HALLIDAY, M. A. K. An Introduction to Functional Grammar. London: Arnold, 1994.

HALliDAY, M. A. K.; HASAN, R. Language, Context, e Text. Aspects of Language in a Social-semiotic Perspective. Oxford: Oxford University Press, 1989.

LYKKE, Nina. Feminist studies: a guide to intersectional theory, methodology e writing. New York/London: Routledge, 2010.

MARTIN, J. R. Beyond exchange: appraisal systems in English. In: Hunston, Susan e Thompson, Geoff (Ed). Evaluation in Text : Authorial Stance e the Construction of Discourse. New York: Oxford University Press, 2001.

MARTIN, J.; WHITE, P. The Language of Evaluation: Appraisal in English. New York: Palgrave/Macmillan, 2005. 
RESENDE, V. M.; RAMALHO, V. Análise de discurso crítica. São Paulo: Contexto, 2006.

. Análise de discurso (para a) crítica: $O$ texto como material de pesquisa. Campinas: Pontes Editores, 2011.

VAN DIJK, Jan. The network Society. London: Sage Publications, 2006.

\section{A AUTORA}

Thais Regina Santos Borges é especialista em Língua Inglesa pela PUC-RJ e bolsista vinculada à CAPES do curso de Mestrado em Estudos da Linguagem da PUC-RJ. Trabalha como professora de inglês e coordenadora da Cultura Inglesa - Filial Botafogo e presta consultoria acadêmica para o departamento de Gerência de Cursos da Cultura Inglesa SA. Tem experiência na área ensino de língua inglesa como língua estrangeira (EFL teaching), análise crítica de discurso, ideologia de gênero, uso do humor na sala de aula de inglês como língua estrangeira. A autora é graduada em Arquitetura e Urbanismo pela UFJF.

E-mail: thaisrsborges@gmail.com

\section{ANEXOS}

ANEXO I - A Entrevista:

YouTube vídeo - Título: \#311 cqc Cortez faz entrevista exclusiva atrizes de Orange Is The New Black 15062015 mircmirc - Disponível em - http://ow.ly/PghEQ

ANEXO II - Exemplos de repercussão:

O GLOBO (online) http://ow.ly/PghS7 Huffington Post USA http://ow.ly/PgihB

UOL $\quad \underline{\text { http://ow.ly/PghZ3 }}$ Huffington Post UK http://ow.ly/PgioH

Catraca Livre $\quad \underline{\text { http://ow.ly/Pgi5z } \quad \text { Huffington Post USA http://ow.ly/Pgimj }}$ 